\title{
Programa médico de família no município de Niterói
}

\author{
SUELY C. S. TEIXEIRA, VALÉRIA DE O. MONTEIRO \\ e VERÓNICA A. MIRANDA
}

$\mathrm{N}$

ITERÓ I É considerado um município de médio porte, localizado na região metropolitana do Rio de Janeiro, com $132 \mathrm{~km}^{2}$ de extensão territorial. Sua população, segundo censo do IBGE de 1996, é de cerca de 517 mil habitantes, com taxa de urbanização de praticamente $100 \%$. Apresenta um cenário de crescimento urbano desigual, coexistindo bairros nobres de estratos sociais de classe média e alta, ao lado de favelas, onde os domicílios têm padrão construtivo precário, concentrando população de baixa renda.

As discussões em torno da reestruturação do Modelo Assistencial de Saúde em Niterói remetem a importantes marcos conceituais surgidos notadamente em meados da década de 80 , com repercussões na política nacional, inserindo o município entre os pioneiros na formulação de propostas voltadas para a Atenção Primária de Saúde - contemplados em AlmaAta/1978, encontrando eco no movimento da Reforma Sanitária e possibilitando o desenvolvimento de mudanças coerentes com a implantação do emergente Sistema Único de Saúde.

Em 1991 concretizou-se um conjunto de decisões políticas para adaptar em Niterói a experiência cubana de medicina familiar e, a partir dessa etapa, foram desenvolvidos estudos preliminares que culminaram com a inauguração do primeiro Módulo do município em setembro de 1992.

Em seu sistema local de saúde, o município compreende atualmente, a partir da Secretaria Municipal de Saúde (Fundação Municipal de Saúde), uma organização hierarquizada em cinco níveis de atenção. O desenho organizacional da Fundação Municipal de Saúde mostra, num primeiro momento, as superintendências como gerência central, a seguir contando com os seguintes equipamentos nos respectivos níveis.

Nível V: seis unidades hospitalares, incluindo infantil, psiquiátrico, cirúrgico, geral (funcionando apenas a maternidade), doenças do tórax e geral universitário. 
Nível IV: central de internações, serviços de pronto atendimento, serviço de atendimento ao usuário, centro de controle de zoonoses, laboratórios.

Nível III: três policlínicas especializadas.

Nível II: cinco policlínicas comunitárias.

Nível I: portas de entrada do sistema, com 14 unidades básicas de saúde (UBS) e 13 módulos do programa médico de família.

A reflexão sobre modelos assistenciais é bastante ampla e envolve vários determinantes: sua concepção, seu arcabouço jurídico e seu sustentáculo técnico operacional. Descrever a construção de um modelo passa por demonstrar o processo histórico no qual foi se conformando, e quais concepções ético-políticas e técnico-organizacionais foram respaldando a direção da prática instituída.

\section{Bases histórico-políticas}

No final da década de 70 o país vivenciava a falência do modelo econômico-social do Estado burocrático-autoritário, o que fez emergirem os movimentos operários e populares demonstrando descontentamento e buscando alianças com outros setores da sociedade civil.

$\mathrm{Na}$ saúde começam a surgir movimentos organizados envolvendo profissionais da área e outros interessados no setor, denunciando a crise do sistema e as más condições de saúde da população. Em decorrência dessa conjuntura é formulada a proposta do Sistema Nacional de Saúde, efetivada pelo Decreto Lei n ${ }^{\circ} 6229 / 75$, visando a reorientar o setor.

A Constituição Federal de 1988 e, posteriormente, as Leis 8080/90 e 8142/91 resultantes da mobilização de setores progressistas pela reforma do sistema de saúde brasileiro, representam o arcabouço legal do Sistema Único de Saúde (SUS). As tentativas de instituir um modelo assistencial organizado por lutas político-institucionais dos atores sociais envolvidos no processo têm resultado em várias experiências, que implementam ações de saúde voltadas principalmente para a melhoria da qualidade da atenção em saúde.

Avanços e retrocessos do SUS têm sido destaque no debate da política pública de saúde no Brasil e, como conseqüência, os municípios vêm desvendando mecanismos próprios no processo de gestão de municipalização da saúde, assumindo a manutenção do setor. 
A partir de 1982 está sendo desenvolvido um processo de aperfeiçoamento das ações de saúde, buscando implementar um modelo capaz de modificar positivamente o perfil de morbi-mortalidade do município. Nesse ano implantou-se o Projeto Niterói, o qual consolidou a hierarquização, integração e regionalização dos serviços municipais de saúde.

Em 1989 iniciaram-se diversos contatos e intercâmbios de experiências entre profissionais de Cuba e de Niterói, quando o município atravessou duas epidemias de Dengue, além de a de Meningite (1991). A partir de então, consolidou-se o intercâmbio técnico-científico que originou o reexame da atenção primária à saúde em Niterói e a elaboração do Projeto médico de família.

Tal aproximação permitiu melhor conhecer a aplicação do Plano de medicina familiar desenvolvido em Cuba, o que resultou em um acordo de assessoria técnica para estudo de viabilidades de adaptação do plano cubano à realidade municipal. Considerou-se que a proposta em questão era compatível com as mudanças interpostas pelo processo de municipalização, ampliando a estratégia de regionalização dos serviços, estabelecendo facilidades de acesso às populações situadas em áreas de risco, definidas pelo diagnóstico ambiental de Niterói feito à época.

A partir do detalhamento dessa estratégia foi elaborado um Projeto de Lei regulamentando as bases do Projeto médico de família, propondo como elemento de sustentação a parceria com o movimento associativo local e definindo uma linha metodológica factível com disponibilidade de recursos financeiros para o setor.

Apesar de as diferenças existentes entre os dois países, Niterói buscou na experiência cubana a viabilidade política de um plano municipal que respondesse aos princípios do SUS. Para tanto, foram levados em conta, entre outros fatores, a humanização do atendimento de forma a facilitar a construção da cidadania e a consciência dos determinantes acerca do processo saúde-doença; a saúde integral da população; e o fortalecimento da promoção à saúde e o estímulo para promovê-la.

\section{Bases técnico-metodológicas}

A medicina familiar significa não somente mudança do modelo de saúde, mas também de filosofia, de enfoque, de forma a entender a realidade, de estudar, de aplicar e de interpretar o processo saúde-doença. Dessa forma a abrangência do Programa Médico de Família (PMF) que ora apresentamos, facilita a compreensão dos fenômenos por meio da conjunção 
do saber clínico, epidemiológico e social, na perspectiva da qualidade de vida da população.

Neste modelo, a acessibilidade dos serviços a uma determinada comunidade, combinada com o diagnóstico local, oferece uma assistência centrada no perfil e nas necessidades da população, estabelecendo assim identidade à porta de entrada do sistema de saúde municipal.

Desde a sua implantação, o Programa médico de família desenvolveu-se pela lógica da reorganização das ações de saúde no município mediante hierarquização e descentralização dos serviços prestados de atenção à saúde, estabelecendo-se como porta de entrada, por excelência, da rede de saúde e integrado aos serviços de maior complexidade.

A seleção de áreas para a implantação do modelo tem sido norteada pela organização social das Associações de Moradores e por fatores de risco locais. As micro-regiões territoriais encontram-se em bairros onde residem populações em riscos social, biológico, epidemiológico e ambiental, levando-se em consideração ao selecioná-las a renda familiar, as condições concretas de trabalho, de subsistência, os problemas de saúde identificados nas pessoas e na coletividade, a estrutura sanitária, a demografia e, conseqüentemente, o risco de adoecer.

A organização popular, representada pelas Associações de Moradores reconhecidas oficialmente pela Federação de Associação de Moradores de Niterói (FAMNIT), constitui representação necessária à formulação do convênio entre estas e a Prefeitura Municipal de Niterói. No convênio foram estabelecidos dois níveis de gerência, compostos pela Fundação Municipal de Saúde (Superintendência de Atenção Ambulatorial e Saúde Coletiva) e pela representação comunitária (liderança das Associações de Moradores).

Os mecanismos de gerência são exercitados em reuniões de setor, para discussão de problemas comuns à situação de saúde coletiva, e em reuniões de avaliação e programação, com a participação contínua dos moradores e/ou sua representação, juntamente com as equipes do PMF de cada localidade. Para resoluções e encaminhamento de questões pendentes é mantido um fórum de discussão permanente entre coordenadores dos Grupos Básicos de Trabalho (GBT) e presidentes das associações, com caráter deliberativo, enfatizando a gestão compartilhada do programa.

O Grupo Básico de Trabalho é constituído por coordenação, equipe de supervisão e equipes básicas. A supervisão é utilizada como instrumento de complementação técnico-metodológica e composta por um grupo de 
especialistas na área de clínica médica, pediatria, toco-ginecologia, saúde pública, enfermagem, serviço social, saúde mental e cirurgia ambulatorial, que trabalha com até 20 equipes básicas. A equipe básica, representada por profissionais de saúde que produzem as ações mais próximas dos usuários, é constituída por um médico e uma auxiliar de enfermagem.

O PMF, embasado na metodologia participativa e nos princípios pedagógicos da educação, cria espaços para a construção da relação dos atores sociais envolvidos: a equipe básica, representada na forma de executores, a supervisão com função gerencial e os usuários da prestação de serviço.

\section{Bases programáticas para a ação}

Definida uma base territorial para a implantação do modelo, inicia-se o mapeamento da área com levantamento e delimitação geográfica. As etapas-chave após o diagnóstico de área consistem em apresentação da metodologia à comunidade, construção do módulo, seleção e treinamento das equipes básicas, setorização, cadastramento e primeiras avaliações para nortear as atividades futuras.

O universo populacional é dividido em setores, atendendo dessa forma a fase de setorização. O número de equipes básicas é proporcional ao número de setores da área, ou seja, cada setor abrangendo 200 a 250 famílias, cerca de 1.000 a 1.200 pessoas residentes adscritas a cada equipe básica. Assim, uma comunidade de quatro mil moradores (média atual) dispõe de até quatro equipes básicas, sendo uma para cada setor constituído.

As equipes básicas ficam instaladas em uma edificação modular, por isto denominada Módulo, construída na própria área, o que facilita o acesso da população à equipe e vice-versa. O módulo é composto de dois consultórios, sala multi-uso, sala de vacinação e nebulização, farmácia, pequena copa, dois banheiros e área livre de recepção e circulação. Cada módulo está equipado com recursos mínimos para funcionamento das atividades cotidianas de uma unidade de atendimento primário

A etapa seguinte compreende a fase de cadastramento: a parcela da população definida na setorização é cadastrada no programa pela equipe básica, iniciando assim um vínculo desta com a população e permitindo um levantamento epidemiológico com estudo detalhado da situação global de cada morador, definindo linhas de ação das mais genéricas às mais específicas.

A metodologia de trabalho implica uma distribuição da carga horária de trabalho semanal $-40 \mathrm{~h}$ - com atendimento em consultório para as situações captadas e livre demanda, em trabalho de campo que objetiva o pro- 
cesso contínuo de conhecimento da realidade, e no espaço estabelecido de educação continuada. O processo de educação continuada desenvolvido pela equipe de supervisão realiza-se nos módulos ou em campo com a visita semanal de cada supervisor e também em um turno fixo semanal com programação elaborada previamente, fora da estrutura dos Módulos.

Desse modo, a equipe multidisciplinar de supervisores complementa as ações da equipe básica, sendo responsável pela capacitação permanente dos profissionais, objetivando garantir a resolutividade dos médicos e auxiliares de enfermagem sobre os problemas diagnosticados. Estes profissionais atuam nos módulos realizando visitas semanais, onde organizam interconsultas, avaliações individualizadas de situações atendidas e discussões dos aspectos inerentes às estratégias operacionais. Cabe a cada equipe de supervisão a responsabilidade de trabalho com até 20 equipes básicas.

\section{Desdobramentos do Programa médico de família}

Até 1996 o sistema de informações em uso no PMF utilizava exclusivamente os dados gerados no sistema de faturamento ambulatorial do $\mathrm{Mi}$ nistério da Saúde e no seu sistema de classificação de procedimentos. Tal conceituação é anterior à própria existência do programa no país, portanto, voltada apenas para a rede ambulatorial tradicional (particularmente a de origem federal).

Em que pese a recente introdução de algumas atividades desenvolvidas no PMF nesse sistema de classificação, de modo geral, a tabela de procedimentos do SIASUS não permite ainda a obtenção de informações representativas do novo modelo de atenção à saúde. Por esse motivo, o PMF desenvolveu um sistema próprio de classificação de procedimentos implantado em janeiro de 1997. Baseia-se numa conceituação de atividades adequadas a sua própria realidade, que incorpora o sistema oficial de produção de dados ambulatoriais, mas não se limita a ele. Voltado para a gerência da situação de saúde de cada população adscrita em particular, do sistema de informação do PMF fazem parte diversos instrumentos de gerência local, cujo objetivo é o de permitir a produção e o consumo de informações.

Todos os esforços têm sido orientados na construção de indicadores que possam aferir as transformações geradas pela intervenção direta nos núcleos de organização familiar e comunitária que possam contribuir efetivamente para a avaliação da melhoria de qualidade de vida nesses segmentos. Dados obtidos no cadastro familiar proporcionam informações que permitem negociações com outros setores envolvidos nas políticas sociais do governo municipal, para a intervenção nessas áreas. 
Assim, destaca-se a criação do Fórum Intersetorial que tem agregado representações das Secretarias Regionais de Educação, Cultura e Meio Ambiente, dentre outras. Esses encontros levam à discussão de soluções viáveis para questões complexas, como urbanização e reflorestamento das áreas de encosta; coleta e reciclagem de lixo; educação profissionalizante e geração de renda, estimulando dessa forma um movimento participativo junto às comunidades.

Com a média de dez mil atendimentos mensais, diversificados em atividades em consultório (cerca de 80\%) e nos domicílios, realização de grupos educativos e reuniões de setor, tem se conseguido manter a cobertura próxima a $100 \%$ das crianças de 0 a 4 anos, $73 \%$ das crianças entre 5 e 14 anos e até $87 \%$ dos adultos acima de 55 anos de idade. Tais índices representam a capacidade de controlar os agravos mais significativos em populações mais expostas às situações de risco.

Registra-se uma inversão progressiva dos motivos de atendimentos realizados pelas equipes do PMF. Destacam-se os fatores que influenciam o estado de saúde sem configurar doenças, ou agravos estabelecidos entre as principais razões de contato dos usuários com o serviço. Em 1997, esses fatores representaram $26,3 \%$ dos motivos de atendimento, seguidos por doenças do aparelho circulatório (10,9\%), sinais e sintomas a esclarecer $(8,4 \%)$ e doenças infecciosas e parasitárias $(7,8 \%)$, mantendo a mesma tendência ao longo do ano de 1998.

A taxa de referência para ambulatórios de especialidades e/ou internações tem oscilado entre 5 e 10\%, aumentando ligeiramente quando se considera o encaminhamento para exames de apoio diagnóstico de maior complexidade. Encontra-se em fase de finalização uma análise de custobenefício, para que se possa demonstrar a viabilidade de expansão do PMF, estendendo assim a sua cobertura.

Outro resultado a ser apontado diz respeito à implementação do Pólo de Capacitação, Formação e Educação Permanente para o pessoal do PSF. Em 1997 o Ministério da Saúde abriu concorrência para a criação desses pólos no país. No estado do Rio de Janeiro, uma proposta que envolve a Fundação Municipal de Saúde de Niterói (FMS), a Universidade Federal Fluminense (UFF) e a Universidade do Rio de Janeiro (UERJ), vem sendo desenvolvida em plena parceria.

A FMS por sua experiência em educação continuada com os profissionais envolvidos na prática de atenção à família ao longo dos seus sete anos de PMF constitui, em conjunto com as universidades, o Pólo do Estado do 
Rio de Janeiro como uma real integração docente-assistencial visando à formação de profissionais capazes de implementar a mudança do modelo de assistência à saúde, baseado nas diretrizes do SUS.

\section{Momento atual}

A implantação do PMF enfrenta alguns desafios e problemas inerentes ao próprio processo: por um lado provocou inúmeras reações por parte dos movimentos sociais representados por Associação dos Servidores Municipais de Saúde, membros dos Conselhos Comunitários de Saúde, além das situações de conflito vivenciadas pelas Unidades Básicas de Saúde conseqüentes do investimento no novo modelo; por outro, a inexistência no mercado de trabalho do profissional médico e auxiliar de enfermagem com a formação e o perfil adequados para a atuação em saúde da família.

Aspecto que também deve ser enfatizado refere-se à nova relação estabelecida com as Associações de Moradores, pela qual seus representantes deixam de ser meros expectadores do processo de participação no poder público e passam a ser parceiros na execução da gerência dos trabalhos, com responsabilidades definidas para ambas as partes. Tal relação, por sua característica inovadora, em algumas situações torna-se fonte geradora de conflitos, que têm de ser administrados na prática diária do trabalho.

Atualmente o PFM está constituído por 45 equipes básicas, representada por 45 médicos e 45 auxiliares de enfermagem, distribuídas em 13 módulos e divididas em três grupos básicos de trabalho, além de uma equipe de supervisão composta por um coordenador e oito supervisores, totalizando três coordenações e 24 supervisores. Na proposta de extensão de alcance do projeto pretende-se ampliar o PFM em 200\%, cadastrando-se 22 mil novas famílias residentes em áreas de risco as quais, somadas às já contempladas pelo modelo, resultariam em cerca de 130 mil pessoas com acesso direto às equipes básicas de saúde.

Referências bibliográficas

LIMA, Pedro Gilberto. Supervisão: algumas considerações para o debate. Documento Instrutivo do Programa Médico de Família. Niterói, 1997 [mimeo].

SENNA, M.C.M. Municipalização e controle social: o Programa médico de família em Niterói. Rio de Janeiro, 1995. Dissertação (mestrado), ENSP/FOC. 
MONNERAT, G.I. Médicos: atores sociais e as mudanças atuais no setor saúde - a experiência do município de Niterói. Rio de Janeiro, 1995. Dissertação (mestrado), ENSP/FOC.

SILVA, Maria Angélica. O Programa médico de familia como estratégia de um novo modelo assistencial: a experiência do município de Niterói-RJ. Rio de Janeiro, 1998. Monografia (Curso de especialização), Faculdade de Serviço Social/UERJ.

Documentos

PMN/SMS/FMS/PMF. PMF: Gestão pública e cidadania, 1997 [mimeo]. - Projeto de implantação do PMF/Niterói [mimeo]. - Relato de experiência, maio 1994 [mimeo]. Relato de experiência, setembro 1994 [mimeo].

Suely C. S. Teixeira é médica pediatra, supervisora de pediatria.

Valéria de O. Monteiro é enfermeira, supervisora de enfermagem.

Verônica A. de Miranda é médica clínica geral e coordenadora.

As autoras exercem suas funções no Grupo Básico de Trabalho II do Programa Médico de Família. 